\title{
KONFLIK IDENTITAS PEREMPUAN DALAM TIGA CERPEN KALIMANTAN TIMUR TAHUN 1980-AN
}

\author{
(Conflict of Women's Identity in Three 1980s East Kalimantan Short Stories)
}

\author{
Diyan Kurniawati \\ Kantor Bahasa Provinsi Kalimantan Timur \\ Jalan Batu Cermin Nomor 25, Sempaja Utara, \\ Samarinda, Kalimantan Timur 75119 \\ Posel: kurniadiyan2018@gmail.com
}

(Naskah Diterima 3 Maret 2020—Direvisi 29 Juli 2020—Disetujui 30 Juli 2020)

\begin{abstract}
This paper presents the position of female characters in three East Kalimantan short stories of the 1980s. They are "Perkawinan", "Buah Hati", and "Luka Cinta". In these short stories, women are in patriarchal culture. It makes women coping with their condition in different ways. Their resistance creates identity conflicts. Using the theory of feminism, this study analyzes the causes and forms of identity conflicts that are experienced by the female character and also the connection between the female character and the others. Descriptive analytics is used to describe and analyze identity conflicts in those short stories. The analysis shows that identity conflicts are caused by patriarchy that continuously make women feel guilty when their struggle is successful. Other characters make positive and negative impacts for women. The positive ones help women to get out of their marginal condition, while the negative ones make women to experience marginal conditions and identity conflicts as well. East Kalimantan short stories of the 1980s show women's struggle in choosing their identity.
\end{abstract}

Keywords: women, identity, patriarchy

\begin{abstract}
Abstrak
Tulisan ini menampilkan posisi tokoh perempuan pada tiga cerpen karya pengarang Kalimantan Timur pada tahun 1980-an. Ketiga cerpen tersebut berjudul "Perkawinan", "Buah Hati", dan "Luka Cinta". Pada cerpen-cerpen tersebut, posisi perempuan berada di tengah-tengah budaya patriarki. Kondisi itu menyebabkan perempuan mengadakan perlawanan dengan pola berbeda-beda. Perlawanan perempuan menimbulkan konflik identitas pada perempuan. Dengan teori feminisme, peneliti menganalisis sebab dan bentuk-bentuk konflik identitas yang dialami tokoh perempuan serta relasi tokoh perempuan dengan tokoh-tokoh lain. Metode deskriptif analitik dilakukan untuk mendeskripsikan dan menganalisis konflik identitas dalam tiga cerpen Kalimantan Timur tahun 1980-an. Analisis menunjukkan konflik bahwa identitas yang terjadi pada perempuan disebabkan patriarki yang secara terus-menerus melakukan upaya agar perempuan merasa melakukan kesalahan apabila perlawanan terhadap kondisinya yang marginal berhasil. Tokoh-tokoh lain menjadi faktor positif dan negatif bagi perempuan. Tokoh yang menjadi faktor positif menyebabkan perempuan keluar dari kondisinya yang marginal. Tokoh yang menjadi faktor negatif menyebabkan perempuan mengalami kondisi yang marginal sehingga mengalami konflik identitas. Cerpen-cerpen Kalimantan Timur tahun 1980-an menunjukkan pergulatan perempuan dalam memilih identitasnya.

Kata kunci: perempuan, identitas, patriarki
\end{abstract}




\section{PENDAHULUAN}

Persamaan gender sudah menjadi fenomena sosial. Perlakuan yang marginal dari pihak pelaku patriarki adalah salah satu sebab persamaan gender tidak tercapai. Dalam relasi gender, dimungkinkan terjadinya konflik identitas yang dialami saat proses perlawanan individu atas kondisi bias gender. Sikap saling menghargai dalam memosisikan diri memengaruhi persamaan gender dapat terjadi. Dalam gender, lakilaki dan perempuan masing-masing mempunyai peran atas diri dan lingkungannya. Gender adalah fakta sosial, pembeda antara peran maskulin dan feminin atau kepribadian (personality) lakilaki dan perempuan (Connel, 2002:68-69). Peran maskulin dan feminin masing-masing mempunyai nilai setara dan penting dalam berbagai ruang. Woodward menjelaskan bahwa identitas dapat diperoleh melalui nasionalisme, sukuisme, kelas sosial, komunitas, gender, dan seksualitas. Sumber-sumber dapat menyebabkan konflik identitas dalam pembentukan posisi identitas dan menimbulkan identitas kontradiktif dan terpisah (Woodward, 1997:1).

Tema mengenai gender sangat banyak ditemukan dalam karya sastra. Tokoh-tokoh perempuan dalam karya sastra sering ditampilkan sebagai individu pejuang atas kondisi yang memarginalkan dirinya. Kondisi bias gender atas dirinya tersebut menyebabkan ia melakukan perlawanan. Proses perlawanan perempuan atas patriarki menjadi fenomena menarik yang penting untuk diteliti. Cerpen-cerpen Kalimantan Timur pada tahun 1980-an mengetengahkan konflik identitas perempuan akibat kondisi bias gender yang terjadi. Perlawanan perempuan atas patriarki tersebut berhadapan dengan identitas sosial yang ditempelkan kepadanya. Hal tersebut menimbulkan konflik identitas perempuan itu sendiri.

Penelitian mengenai gender telah banyak dilakukan. Dalam dijelaskan mengenai konflik gender yang terdapat dalam cerpen-cerpen Kalimantan Timur (Kurniawati, 2014). Perempuan mengalami posisi marginal karena konflik tersebut. Penelitian tersebut menjelaskan bentukbentuk perlawanan tokoh perempuan atas patriarki, yaitu secara frontal dan nonfrontal. Sementara itu, dalam Zuraida, dkk. diungkapkan mengenai pemberontakan perempuan dalam novel Perempuan Badai karya Mustofa Wahid Hasyim. Penelitian itu mengungkapkan posisi perempuan pada zaman sekarang yang berada dalam posisi yang rumit. Apabila perempuan tidak mengikuti arus perubahan, perempuan dianggap layak dipinggirkan (Tia Ratna Zuraida, n.d.). Sementara itu, apabila perempuan mengikuti arus perubahan, dianggap kehilangan identitas. Permasalahan gender juga terdapat dalam Kusuma dan Nuryanto (Nuryanto, 2019). Dalam penelitian tersebut disoroti permasalahan gender dalam cerpen "Rambutnya Juminten" karya Ratna Indraswari Ibrahim. Penelitian tersebut mengungkapkan terdapat gambaran nyata masyarakat dalam memandang perbedaan gender. Perbedaan gender menjadi pembatas peerempuan untuk berkarya dan beraktivitas dan laki-laki bersikap bahwa perempuan memandang berlebihan mengenai feminisme.

Miyasari mengungkapkan pula mengenai persoalan gender yang terdapat dalam novel Perempuan Pantai Karya Pramoedya Ananta Toer dan Tanah Tabu karya Anindita S Thayf (Miyasari, 2019). Melalui kajian sastra bandingan, penelitian tersebut membandingkan persamaan dan perbedaan permasalahan gender dalam kedua novel. Kedua novel tersebut samasama mengungkapkan mengenai ketidakadilan gender bagi perempuan, melalui bentuk marginalisasi, subordinasi, dan stereotip. Sementara itu, bentuk kekerasan fisik terjadi pada perempuan dalam novel Tanah Tabu. Dalam novel Perempuan Pantai, perempuan mengalami kekerasan nonfisik berupa kekayaan dan 
kekuasaan yang dimiliki laki-laki. Sunahrowi dan Damayanti menyebutkan mengenai ketidaksetaraan gender yang terdapat dalam Roman L'enfant De Sable Karya Tahar Ben Jelloun (Damayanti \& Sunahrowi, 2017). Posisi laki-laki dianggap lebih penting daripada perempuan. Perempuan dianggap sebagai manusia kelas dua dan sifat-sifat negatif dilekatkan pada perempuan. Penelitian-penelitian tersebut menampilkan ketidakadilan gender yang dialami perempuan. Kondisi ini menyebabkan perempuan mengalami bentuk-bentuk marginalisasi dan tidak dianggap manusia yang penting.

Akan tetapi, penelitian-penelitian tersebut belum mengungkapkan secara detail mengenai konflik identitas yang terjadi kepada perempuan saat perlawanan terhadap patriarki terjadi. Oleh karena itu, masalah yang akan dibahas dalam penelitian ini ialah bagaimana sebab perempuan mengalami konflik identitas dan bagaimana bentuk konflik identitas perempuan pada proses melakukan perlawanan patriarki? Tujuan penelitian ialah mengetahui sebab perempuan mengalami konflik identitas dan mengetahui bentuk-bentuk konflik identitas perempuan pada proses melakukan perlawanan terhadap patriarki. Cerpencerpen yang akan diteliti ialah cerpen "Perkawinan", "Buah Hati", dan "Luka Cinta".

Penelitian ini menggunakan teori feminisme untuk mengkaji konflik identitas perempuan di tengah-tengah budaya patriarki.

Dalam Tong disebutkan dalam feminisme radikal-libertarian, menurut Millet, marginalisasi yang dialami perempuan disebabkan karena sistem seks dan gender dalam patriarki (Tong, 2008:73). Ideologi patriarki menyebutkan perbedaan biologis antara laki-laki dan perempuan. Laki-laki mempunyai peran maskulin yang dominan. Sementara itu, perempuan mempunyai peran feminin yang subordinat.
Dalam Connell dijelaskan pula bahwa gender ialah relasi sosial yang diatur oleh sebuah struktur dan dibawa ke dalam proses sosial. Pengaturan gender direproduksi secara sosial (bukan secara biologis) oleh struktur kekuasaan (Connel, 2002:9-10). Connell mengungkapkan pula bahwa relasi gender yang berlangsung tersebut telah memungkinkan sistem patriarki. Humm menyebutkan bahwa patriarki adalah suatu sistem otoritas lakilaki melalui institusi sosial, politik, dan ekonomi yang membuat perempuan mengalami ketidakadilan (Humm, 2002:69). Figes juga menjelaskan sikap patriarki telah berlangsung secara terus menerus dan secara fundamental tetap ada di setiap generasi (Figes, 1986). Sikap patriarki dibentuk oleh memori-memori kita. Hal tersebut dimulai dalam struktur keluarga pada masa kanak-kanak, melalui citra ayah dan ibu. Menurutnya, konsep patriarki juga terdapat dalam berbagai pemikiran di bidang ilmu pengetahuan. Pemikiran laki-laki diterima secara umum dalam seluruh bidang. Dalam urutan piramid, laki-laki menempatkan dirinya pada urutan yang paling atas. Sementara itu di bidang filsafat, para filsuf menganggap bahwa laki-laki adalah bentuk yang mutlak atau penuh dan karena hal tersebut, perempuan harus menjadi sesuatu yang kurang. Di bidang psikologi, norma-norma tingkah laku manusia diidentifikasikan dengan tingkah laku laki-laki sehingga dalam beberapa pengertian, perempuan selalu dianggap sebagai abnormal. Sistem patriarki yang menempatkan perempuan dalam tataran rendah tersebut ditentang oleh Figes (Figes, 1986:111-113).

Perempuan dalam cerpen-cerpen tersebut mempunyai bentuk perlawanan patriarki yang berbeda-beda. Bentuk pemilihan identitas atas situasi yang terjadi di sekitarnya dengan demikian berbeda pula. Dengan demikian, konsep identitas diperlukan dalam penelitian ini.

Konflik identitas dapat terjadi dalam gender sebagai salah satu sumber 
pemerolehan identitas. Middleton menjelaskan bahwa identitas adalah jalan untuk menggambarkan diri dan memainkan peranan kita dalam konteks sosial. Woodward juga menyatakan bahwa identitas diperoleh dari berbagai macam sumber, yaitu melalui nasionalisme, sukuisme, kelas sosial, komunitas, gender, dan seksualitas (Woodward, 1997). Sumber-sumber tersebut dapat menimbulkan konflik identitas dalam pembentukan posisi identitas dan menimbulkan identitas kontradiktif dan terpisah. Akan tetapi, identitas memberi kita tempat di dunia dan menjadi penghubung antara kita dengan masyarakat tempat kita hidup. Identitas juga memberi kita ide tentang siapa dan bagaimana kita berhubungan dengan orang lain dan dunia tempat kita tinggal. Stuart Hall, dkk. menjelaskan pula bahwa identitas diproduksi, digunakan, dan diatur dalam kebudayaan. Identitas terbentuk maknanya melalui representasi posisi yang kita ambil (Woodward, 1997:2).

\section{METODE PENELITIAN}

Untuk mengetahui bentuk dan sebab konflik identitas perempuan pada tiga cerpen Kalimantan Timur tahun 1980-an, penelitian ini menggunakan metode deskriptif analitik. Dalam Ratna disebutkan bahwa metode deskriptif analitik dilaksanakan dengan cara mendeskripsikan fakta-fakta dan kemudian dilakukan analisis (Ratna, 2008:53). Dalam tulisan ini, metode deskriptif analitik diterapkan dengan mendeskripsikan tokoh perempuan dalam tiga cerpen Kalimantan Timur tahun 1980an kemudian menganalisis sebab perempuan mengalami konflik identitas dan bentuk-bentuk konflik identitas yang dialami perempuan. Tokoh-tokoh yang mempunyai relasi dengan perempuan juga dianalisis.

Langkah-langkah yang dilakukan untuk mengetahui sebab serta bentuk konflik identitas yang terjadi pada perempuan ialah (1) menentukan data primer penelitian, yaitu cerpen Kalimantan Timur tahun 1980-an yang dipublikasikan dalam surat kabar Manuntung. Judul cerpen-cerpen tersebut ialah "Perkawinan" karya Ny Jerie (27 Agustus 1988), "Luka Cinta" karya Rusyarani (20 Februari 1989), dan "Buah Hati" karya Eriko (23 Februari 1989); (2) mendeskripsikan tokoh perempuan dalam tiga cerpen Kalimantan Timur tahun 1980-an; (3) menganalisis sebab dan bentuk konflik identitas yang dialami tokoh perempuan dalam cerpencerpen tersebut; (4) menganalisis relasi tokoh perempuan dengan tokoh-tokoh di sekitarnya; (5) menentukan posisi tokoh perempuan di tengah-tengah konflik identitas yang dialaminya.

\section{PEMBAHASAN}

Tiga cerpen Kalimantan Timur tahun 1980an menampilkan tokoh perempuan di tengah-tengah lingkungan sosialnya. Perempuan mengalami konflik identitas karena perlawanannya atas perbedaan pemilihan identitas perempuan dengan lingkungan sosialnya. Tokoh-tokoh lain yang mempunyai relasi dengan tokoh-tokoh perempuan menjadi faktor negatif atau positif bagi tokoh perempuan.

\section{Posisi Tokoh Perempuan dalam Lingkungan Sosial}

Cerpen "Perkawinan" menampilkan tokoh Ratih yang tidak diperbolehkan melanjutkan pendidikan ke universitas oleh orang tuanya. Tokoh Ratih ditampilkan sebagai tokoh anak yang diperlakukan secara berbeda daripada kakaknya. Kakaknya, Wito, diperbolehkan melanjutkan kuliah. Hal tersebut karena Ratih adalah seorang perempuan. Orang tuanya memintanya untuk segera menikah dan menjadi ibu rumah tangga setelah lulus SMA.

Ayah dan Ibu ditampilkan sebagai ikon patriarki yang membedakan kebebasan 
pendidikan antara anak perempuan dan anak laki-lakinya.

Tetapi kenapa Mas Wito dikuliahkan?" aku protes terhadap kakakku yang dikuliahkan di Jakarta.

"Masmu itu laki-laki sedangkan kau perempuan, Ratih!" ibuku ikut nimbrung. (Jerie, 1988, hlm. VI)

"Mbakyumu dulu SMP saja, sekarang hidupnya senang mendampingi suaminya mengasuh anak-anaknya," lagi-lagi ibuku yang menyahut (Jerie, 1988, hlm. VI)

Kutipan tersebut menunjukkan perbedaan perlakuan antara laki-laki dan perempuan. Anak perempuan di keluarga tersebut setelah lulus SMA harus segera menikah dan menjadi ibu rumah tangga. Penolakan terhadap aturan tersebut dianggap perlawanan terhadap orang tua. Tokoh ayah dan ibu meyakinkan anak perempuannya bahwa pendidikan bagi perempuan cukup sebatas SMA. Ibu rumah tangga adalah pilihan yang membahagiakan.

Sementara itu, dalam cerpen "Luka Cinta" ditampilkan tokoh perempuan yang dikhianati oleh kekasihya. Tokoh Aku merasa dikhianati oleh Al, kekasihnya. Al diketahuinya telah bermesraan dengan perempuan lain. Ia merasa marah dan sedih. Pengorbanan yang ia lakukan tidak ada artinya.

Kukorbankan semua yang kumiliki hanya untuk mencapai kebahagiaan itu, untuk itu aku mengorbankan perasaan orang yang juga sangat kukasihi, dialah ibuku yang telah melahirkanku. Biarlah orang berkata yang bukan-bukan, asal kau masih percaya padaku....

Begitu mesranya kau dengan gadis berambut sebahu itu, tertawa, gembira, sementara aku berdiri terpaku menahan tangis. Inikah hasil dare perjuangan yang kupertahankan selama ini? (Rusyarani, 1989, hlm. VI)

Kutipan tersebut menunjukkan tokoh Aku sangat kecewa atas perilaku Al. Tokoh Aku ditampilkan sudah mengacuhkan nasihat ibunya demi tetap bersama Al. Tokoh Al merupakan ikon patriarki yang tidak menghargai tokoh Aku.

Tokoh perempuan mengalami kekerasan nonverbal. Perilaku yang dilakukan individu lain mengakibatkan individu mengalami sakit hati. Individu lain melakukan pengkhianatan atas janji yang telah mereka sepakati. Pengorbanan yang dilakukan perempuan tidak berbanding lurus dengan keadaan yang ia alami.

Tokoh Aku selanjutnya kembali ke kota kelahirannya untuk melanjutkan sekolahnya. Ia masih berharap dapat kembali kepada Al.

Pertengahan juni aku kembali dan bermaksud melanjutkan sekolah di sini. Ketika itulah aku berjanji merajut benangbenang kasih yang pernah terputus, walaupun untuk itu aku harus berkorban. Ternyata kau tak mudah diraih. ... Kembalilah ke jalan yang lurus, hentikan petualanganmu yang tak pernah ada akhirnya. Aku akan selalu menantimu (Rusyarani, 1989, hlm. VI)

Kutipan tersebut menunjukkan perempuan mengalami ketidakkonsistenan perilaku. Keadaan yang tidak menyenangkan akibat perilaku individu lain telah dilupakannya. Akar tempat kelahiran yang dahulu dijauhi karena ingin melupakan kejadian akibat individu lain kini ditinggalinya kembali. Perempuan bahkan mencoba mendekat kembali dengan individu lain yang semula ingin dilupakannya.

Cerpen "Buah Hati" menampilkan sebuah keluarga yang belum mempunyai keturunan. Irma dan Pri ditampilkan sebagai suami istri yang belum mempunyai keturunan. Keadaan tersebut membuat ibu mertua Irma mencampuri urusan tersebut. Ia mempermasalahkan Irma dan Pri yang belum mempunyai keturunan. Ibu mertua Irma menyuruh Irma untuk mencari tahu penyebab mereka tidak segera punya keturunan. 
"Kalau Pri tak mungkin mandul. Semua kakaknya sudah punya anak semua," suara ibu mertuanya kembali terngiang, Irma tersinggung, "Jadi mereka anggap aku yang mandul?"

"Anak itu penting, Ma. Kan orang kawin karena ingin punya keturunan. Makanya kau harus berusaha. Nggak sempurna kalau wanita nggak bisa punya anak," kata ibunya mertuanya lagi. Irma hanya diam sampai mertuanya pulang (Eriko, 1989, hlm. VI)

Kutipan tersebut menunjukkan konflik antara menantu, Irma, dan ibu mertuanya. Irma sebagai menantu dituntut harus selalu berusaha dalam hal mempunyai keturunan. Secara tidak langsung, ibu mertua juga menuduh Irma sebagai pihak yang mandul. Konflik tersebut tidak terjadi secara frontal karena Irma hanya bersikap diam.

Posisi perempuan ditampilkan lemah di hadapan perempuan lain, yaitu ibu mertua. Ibu mertua menyalahkan menantunya karena anak dan menantunya belum mempunyai anak. Sementra itu, anak laki-lakinya dianggap tidak bersalah dalam masalah tersebut. Perempuan hanya bisa pasrah dengan perlakuan tersebut. Tidak ada konflik frontal di antara keduanya

\section{Sebab dan Bentuk-Bentuk Konflik Identitas Perempuan}

Pada cerpen "Perkawinan", konflik identitas terjadi saat Ratih mengetahui bahwa orang tua menyiapkan jodoh bagi dirinya. Tokoh Ratih setelah pergi meninggalkan rumah merasa bersalah karena telah pergi dari rumah tanpa izin. Ia meminta maaf kepada ayah dan ibunya. Orang tua telah menyiapkan jodoh bagi dirinya.

"Calon suamimu Ratih!" ayah seakan tahu isi hatiku ....

.... Aku harus membuka lembaran baru dalam hidupku. ... itu mengoyak segala cita harapan.... Dan aku tidak tahu apakah aku bahagia memiliki perkawinan (Jerie, 1988, hlm. VI)
Kutipan tersebut menunjukkan konflik identitas perempuan atas keputusan yang diambilnya. Perlawanan terhadap kondisi patriarki tidak mengalami keberhasilan karena keraguan perempuan atas keputusan yang diambilnya. Identitas yang dipilihkan kepadanya menyebabkan perempuan mengalami konflik identitas.

Sementara itu, pada cepen "Luka Cinta", konflik identitas terjadi saat tokoh perempuan berada di kota lain untuk melupakan sakit hati terhadap tokoh Al. Di kota lain, Aku tetap mengikuti perkembangan Al. Ia sempat merasa senang ketika Al tidak lulus ujian. Ia merasa sakit hatinya terbalaskan.

Belum setahun aku di sini, aku menerima kabar dari sahabatku bahwa kau tidak lulus ujian,... Aku gembira mendengar berita itu, walaupun aku menyadari itu tercela di mata Tuhan. Aku merasa sakit hatiku terbalaskan,... (Rusyarani, 1989, hlm. VI)

Kutipan tersebut menunjukkan tokoh Aku mengalami konflik identitas. Di satu sisi, ia sakit hati terhadap tokoh Al. Akan tetapi, tokoh masih mengikuti perkembangan tokoh Al. Bahkan, pada akhirnya, tokoh Aku ingin kembali kepada tokoh Al.

Tokoh perempuan dalam cerpen tersebut ditampilkan mengalami konflik identitas karena sikap yang dipilihnya sendiri. Ia mengikuti perasaan dan melupakan perlawanan yang pernah dipilihnya.

Pada cerpen "Buah Hati", perempuan mengalami konflik identitas saat ia tidak mempunyai pilihan lagi di tengah-tengah kondisi yang terjadi pada dirinya. Tokoh perempuan bersikap menerima hal yang akan diperbuat suami dan mertua.

"Mas kalau kau yang mandul, aku bisa menerima. ... Kau tahu kan, aku tak ada sanak keluarga lagi. Aku merasa hidup bahagia bersamamu dan itu sudah cukup. Tetapi kalau aku yang mandul, Aku pun tak 
menghalangimu buat kawin lagi. Aku terima. Pasrah...," suara Irma terdengar pelan ('Rusyarani, 1989, hlm. VI)

Kutipan tersebut menampilkan konflik identitas pada diri perempuan. Kepasrahan yang ia lakukan merupakan bentuk konflik identitas yang disebabkan secara sosial ekonomi ia tidak dapat hidup tanpa keluarganya. Perempuan bersikap menerima apabila ada perlakuan negatif yang akan terjadi pada dirinya.

\section{Relasi Perempuan dengan Tokoh Lain: Faktor Positif dan Negatif}

Pada tiga cerpen Kalimantan Timur tahun 1980-an, ditampilkan pula relasi perempuan dengan tokoh lain yang menjadi faktor bagi konflik identitas yang dialaminya.

Dalam cerpen "Perkawinan", ditampilkan relasi di ruang keluarga antara tokoh perempuan dengan tokoh ayah dan tokoh ibu. Perbedaan perlakukan antara anak laki-laki dan anak perempuan ditampilkan dalam cerpen tersebut. Anak laki-laki diperbolehkan menjalani pendidikan yang lebih tinggi daripada perempuan. Ratih sebagai salah satu anak perempuan di keluarga tersebut sangat prihatin atas keputusan orang tuanya.

.... kendati ayah dan ibu masih keturunan ningrat. Entah keturunan yang keberapa. Tetapi itu bukan alasan untuk mendikteku dengan cara lama... Laki-laki dan perempuan sama derajatnya. Sama mempunyai hak dan kewajiban... Mengapa ayah masih saja menutup mata terhadap perubahan zaman (Jerie, 1988, hlm. VI).

Kutipan tersebut menunjukkan keprihatinan anak perempuan terhadap budaya yang terjadi dalam keluarganya. Ia menginginkan laki-laki dan perempuan mempunyai hak dan kewajiban yang sama, terutama dalam pendidikan. Tokoh ayah ditampilkan menjadi faktor negatif bagi tokoh perempuan.
Relasi tokoh perempuan dengan tokoh ibu juga ditampilkan dalam cerpen tersebut. Relasi dengan tokoh ibu ditampilkan melalui perbedaan pandangan tokoh Ratih dengan tokoh ibu.

"Tetapi kenapa Mas Wito dikuliahkan?" aku protes terhadap kakakku yang dikuliahkan di Jakarta.

"Masmu itu laki-laki sedangkan kau perempuan, Ratih!" ibuku ikut nimbrung (Jerie, 1988, hlm. VI).

Kutipan tersebut menunjukkan tokoh ibu sebagai tokoh negatif bagi tokoh perempuan. Tokoh Ibu sebagai perempuan juga mendukung keputusan suaminya untuk membatasi pendidikan anak-anak perempuannya.

"Mbakyumu dulu SMP saja, sekarang hidupnya senang mendampingi suaminya mengasuh anak-anaknya," lagi-lagi ibuku yang menyahut.

"Saya ingin kelak mempunyai fungsi lain di samping mengurus keluarga, bu!" aku membela diri (Jerie, 1988, hlm. VI).

Kutipan tersebut menunjukkan tokoh relasi antara tokoh ibu dan tokoh perempuan (anak) yang mengalami konflik. Tokoh perempuan (anak) mengemukakan bahwa keputusannya melanjutkan sekolah adalah hal yang sangat bermanfaat, juga ketika ia berumah tangga.

Perlawanan tokoh Ratih atas keputusan orang tuanya tersebut dilakukan dengan cara mengurus sendiri perlengkapan masuk ke perguruan tinggi. Namun, orang tua akhirnya mengetahui hal tersebut. Tokoh Ratih diminta tidak lagi memikirkan masalah kuliah karena ia akan segera dijodohkan.

"Aku pun segera duduk. Kulirik map yang dipegang ayah. Oh, mapku yang isinya perlengkapan masuk perguruan tinggi....

"Sudah! Tidak usah lagi kau beranganangan untuk kuliah. Kau akan segera 
menikah dengan Handono!" kata ayah yang kemudian merobek-robek mapku.

Segera kupunguti map yang telah dirobek ayah, lalu kudekap bagai aku mendekap hatiku yang hancur (Jerie, 1988, hlm. VI).

Kutipan tersebut menunjukkan kegagalan individu untuk meyakinkan orang tuanya bahwa pendidikan adalah hal penting bagi perempuan.

Keputusan tokoh orang tua menyebabkan tokoh perempuan mengalami konflik identitas.

... aku bergegas meninggalkan rumah. Apakah ini dosa?... Aku tidak tahu yang jelas hatiku berontak tidak dapat menerima semua ini (Jerie, 1988, hlm. VI)

.... Aku harus membuka lembaran baru dalam hidupku. ... itu mengoyak segala cita harapan.... Dan aku tidak tahu apakah aku bahagia memiliki perkawinan (Jerie, 1988, hlm. VI)

Kutipan tersebut menunjukkan tokoh ayah dan ibu menjadi faktor negatif bagi tokoh perempuan. Keputusan tokoh ayah dan ibu terhadap identitas perempuan menyebabkan tokoh perempuan mengalami konflik identitas yang berkepanjangan.

Sementara itu, dalam cerpen "Luka Cinta" ditampilkan relasi antara tokoh Aku dengan tokoh $\mathrm{Al}$ dan tokoh Papa. Tokoh $\mathrm{Al}$ Al ditampilkan sebagai faktor negatif bagi tokoh perempuan.

Begitu mesranya kau dengan gadis berambut sebahu itu, tertawa, gembira, sementara aku berdiri terpaku menahan tangis. Inikah hasil dari perjuangan yang kupertahankan selama ini? (Rusyarani, 1989, hlm. VI)

Kutipan tersebut menunjukkan tokoh $\mathrm{Al}$ yang menjadi faktor negatif bagi tokoh perempuan. Perempuan melakukan pertahanan identitas dengan meninggalkan kota kelahirannya.
Setelah perpisahan denganmu akhirnya aku menerima anjuran papa untuk melanjutkan sekolah di sana, kuhitunghitung apa salahnya aku pergi sembari melupakan kenangan pahit yang baru saja kualami (Rusyarani, 1989, hlm. VI).

Kutipan tersebut menunjukkan individu melakukan pertahanan identitas diri dengan meninggalkan akarnya. Dengan jauh dari akarnya, individu berupaya melupakan memori yang baru saja ia alami. Tokoh Papa ditampilkan mendukung tokoh Aku untuk melupakan memori dengan tokoh Al. Tokoh Papa ditampilkan sebagai faktor positif bagi tokoh perempuan untuk melupakan memorinya dengan tokoh lain.

Pada cerpen "Buah Hati" ditampilkan relasi perempuan dengan tokoh suami dan mertua. Tokoh perempuan dan tokoh suami ditampilkan belum mempunyai keturunan. Tokoh suami, Pri, di ruang keluarga tersebut ditampilkan tidak menyalahkan tokoh istri, Irma, atas masalah belum adanya anak dalam keluarga mereka. Suruhan ibunya untuk menikah lagi tidak diturutinya.

"Yah, ibu menyuruhku kawin lagi," Irma terdiam. Inilah yang dia tunggu. Inilah yang mengakhiri kebahagiaannya....

"Ibu benar, Mas. Kau harus mendapatkan keturunan," sahut Irma pendek.

"Kau pikir semudah itu aku kawin lagi," tanyanya tersenyum. ...

"Aku tak akan meninggalkanmu, Ma," bisik Pri di telinga Irma.

"Apa pun yang terjadi, kita hadapi berdua dengan bekal ketabahan hati kita, sambung Pri lagi (Eriko, 1989, hlm. VI)

Kutipan tersebut menampilkan tokoh suami sebagai tokoh positif bagi tokoh perempuan. Sementara itu, tokoh mertua ditampilkan sebagai tokoh negatif bagi tokoh perempuan karena meminta tokoh suami meninggalkan istrinya. Kutipan tersebut juga menunjukkan posisi perempuan yang menerima konsekuensi belum adanya keturunan. Perempuan 
bersikap menerima segala hal yang akan diperbuat suami dan mertua.

"Mas kalau kau yang mandul, aku bisa menerima. ... Kau tahu kan, aku tak ada sanak keluarga lagi. Aku merasa hidup bahagia bersamamu dan itu sudah cukup. Tetapi kalau aku yang mandul, aku pun tak menghalangimu buat kawin lagi. Aku terima. Pasrah...," suara Irma terdengar pelan (Eriko, 1989, hlm. VI)

Kutipan tersebut menampilkan posisi perempuan yang lemah. Ia menerima semua hal yang akan terjadi padanya. Hal itu disebabkan ia lemah secara sosial ekonomi. Perempuan bersikap menerima apabila ada perlakuan negatif yang akan terjadi kepada dirinya.

Tokoh suami yang menjadi faktor positif, menjadikan perempuan kemudian menyelesaikan persoalan dengan pengangkatan anak. Selain sisi kemanusiaan, pengangkatan anak juga dimaksudkan sebagai upaya untuk mendapatkan keturunan.

\section{PENUTUP}

Tiga cerpen Kalimantan Timur tahun 1980an menunjukkan posisi tokoh perempuan di tengah-tengah lingkungan sosialnya. Tokoh perempuan mengalami konflik identitas karena pilihan identitasnya berbeda dengan identitas yang dipilihkan terhadapnya. Perlawanan yang dilakukan perempuan terhadap kondisi tersebut menyebabkan perempuan mengalami konflik identitas.

Konflik identitas yang dialami perempuan terjadi karenan ikon patriarki melakukan upaya untuk mendoktrin perempuan bahwa perlawanan yang dilakukan perempuan atas kondisinya yang marginal adalah hal yang salah. Perempuan tidak mempunyai pilihan selain mengikuti alur yang telah ditetapkan ikon patriarki karena secara sosial ekonomi rendah. Penerimaan kondisi tersebut menyebabkan perempuan mengalami konflik identitas yang berkepanjangan.
Tiga cerpen Kalimantan Timur tahun 1980-an tersebut menunjukkan bahwa perempuan yang lemah secara sosial ekonomi pada akhirnya mengambil keputusan mengikuti identitas sosial di tengah-tengah konflik identitas yang terjadi pada dirinya. Perempuan tidak dapat memilih identitas dirinya sendiri.

\section{DAFTAR PUSTAKA}

Connel, R. (2002). Gender. Cambridge: Polity Press.

Damayanti, G. P., \& Sunahrowi. (2017). Identitas dan Posisi Perempuan dalam Roman L'enfant De Sable Karya Tahar Ben Jelloun. Suar Betang, 12(1), 1-10.

Eriko. (n.d.). Buah Hati. In Manuntung VI.

Figes, E. (1986). Patriarchal Attitudes: Women in Society. MacMillan Education.

Giles, J., \& Middleton, T. (n.d.). Studying Culture: A Practical Introduction. Oxford: Blackwell Publishing.

Humm, M. (2002). Ensiklopedia Feminisme. Yogyakarta: Fajar Pustaka Baru.

Jerri, N. (1988). Perkawinan. In Manuntung VI.

Kurniawati, D. (2014). Konflik Gender dalam Ruang Keluarga dalam Cerpen Kalimantan Timur. Loa, 9(1), 49-58.

Miyasari, T. N. (2019). Ketidakadilan Gender dalam Novel Gadis Pantai Karya Pramoedya Ananta Toer dan Tanah Tabu Karya Anindita S. Thayf. Alayasastra, 15(1), 27-44.

Nuryanto, K. D. dan T. (2019). Feminisme dalam Cerpen "Rambutnya Juminten" karya Ratna Indraswari Ibrahim. Indonesian Languange Education and Literature, 4(2), 240--256.

Ratna, N. K. (2008). Teori, Metode, dan Teknik Penelitian Sastra. Yogyakarta: Pustaka Pelajar.

Rusyarani. (n.d.). Luka Cinta. In Manuntung VI. 
Tia Ratna Zuraida, D. (n.d.). Pemberontakan Perempuan dalam Novel Perempuan Badai Karya Mustifa Wahid Hasyim: Kajian Feminisme. Sastra Indonesia, 2(1), 110.

Tong, R. (2008). Feminis Thought: Pengantar Paling Komprehensif kepada Arus Utama Pemikiran Feminis. Jakarta: Jalasutra.

Woodward, K. (1997). Identity and Difference. London: Sage Publications. 